\title{
Re-Thinking Shared Decision-Making: Context Matters
}

\author{
Marianne S. Matthias, PhD \\ Research Scientist, VA HSR\&D Center on Implementing Evidence-Based Practice, Roudebush \\ Veterans Affairs Medical Center; Research Scientist, Regenstrief Institute, Inc; Adjunct Assistant \\ Professor, Department of Communication Studies, Indiana University-Purdue University \\ Indianapolis (IUPUI) \\ Michelle P. Salyers, PhD \\ Associate Professor, Department of Psychology, IUPUI; Co-Director, ACT Center of Indiana; \\ Research Scientist, Regenstrief Institute, Inc \\ Richard M. Frankel, PhD \\ Senior Research Scientist, VA HSR\&D Center on Implementing Evidence-Based Practice, \\ Roudebush VAMC and Regenstrief Institute, Inc; Director, Mary Margaret Walther Center for \\ Research and Education in Palliative Care, Professor of Medicine and Geriatrics, Indiana \\ University School of Medicine
}

\section{Corresponding Author:}

Marianne S. Matthias, Ph.D.

Roudebush VA Medical Center

1481 W. 10th St. $(11 \mathrm{H})$

Indianapolis, IN 46202

Email: mmatthia@iupui.edu

Phone: 317.988.4514

Fax: 317.988 .3222

Running Head: Re-Thinking Shared Decision-Making

Funding: This study was funded by a Department of Veterans Affairs Health Services Career Development Award (CDA 10-034). The views expressed in this article are those of the authors and do not necessarily reflect the position or policy of the Department of Veterans Affairs or the United States government.

Accepted version; Final version published as Matthias, M. S., Salyers M. P., \& Frankel, R. M. (2013). Re-Thinking Shared Decision-Making: Context Matters. Patient Education and Counseling, 91(2), 176-179. 


\title{
Re-Thinking Shared Decision-Making: Context Matters
}

\begin{abstract}
Objective: Traditional perspectives on shared decision-making (SDM) focus attention on the point in a clinical encounter where discussion of a treatment decision begins. We argue that SDM is shaped not only by initiation of a treatment decision, but by the entire clinical encounter, and, even more broadly, by the nature of the patient-provider relationship.

Method: The Four Habits Approach to Effective Clinical Communication, a validated and widely used framework for patient-provider communication, was used to understand how SDM is integrally tied to the entire clinical encounter, as well as to the broader patient-provider relationship.

Results: The Four Habits consists of four categories of behaviors: 1) Invest in the beginning; 2) Elicit the patient's perspective; 3) Demonstrate empathy; and 4) Invest in the end. We argue that the behaviors included in all four of these categories work together to create and maintain an environment conducive to SDM.

Conclusion: SDM cannot be understood in isolation, and future SDM research should reflect the influence that the broader communicative and relational contexts have on decisions.

Practice Implications: SDM training might be more effective if training focused on the broader context of communication and relationships, such as those specified by the Four Habits framework.
\end{abstract}

Key Words: shared decision-making, patient-provider communication, patient-centeredness 


\section{Re-Thinking Shared Decision-Making: Context Matters}

1. Introduction

We argue in this commentary for an expanded view of shared decision-making (SDM). Using The Four Habits Approach to Effective Clinical Communication (1-6), we demonstrate that SDM is shaped by the entire clinical encounter- not just the point where a decision is madeand, even more broadly, by the nature of the patient-provider relationship (e.g., length, degree of alliance/trust). Our goal is to advance thinking about SDM, while challenging researchers to find more effective and innovative ways of studying this phenomenon.

2. SDM in Health Care

SDM has been widely advocated. Policy makers promote SDM because of its potential to increase use of beneficial treatment options, decrease utilization of treatment options without clear benefits, decrease variations in health care delivery, and promote patients' involvement in their own health.(7) Philosophically, SDM is important because patients must live with the consequences of treatment decisions, including side effects, risks, benefits, and other effects on their day-to-day lives. Moreover, if a patient is involved in a treatment decision, they are more likely to implement-and maintain - the treatment, thereby increasing adherence and improving outcomes of care. $(8 ; 9)$

SDM is also advocated for ethical reasons $(10 ; 11)$, with a patient's involvement in his or her health care described as a fundamental right.(12) Part of the ethical argument concerns patients' rights to be informed about and consent to treatments, based on individual autonomy and bodily integrity (13). SDM moves beyond informed consent, which is primarily a legal obligation that does not necessarily seek to ensure comprehension of treatment goals 
and options, risks, and benefits.(14) SDM is an interactive process that involves sharing information and opinions, discussing patient preferences and provider responsibilities, and mutual agreement on a course of action. (8;15-20)

Elwyn and colleagues (30) have argued that patients should be involved in decisions whenever options exist, noting few interventions are completely free from harm. They add that patients have perspectives providers do not have: an understanding of social and psychological consequences of decisions, in contrast to a provider's use of medical evidence, which is almost always confined to biomedical consequences.(21) Physicians do not always understand patients' health beliefs, making patient involvement critical (22).

Charles and colleagues describe four essential attributes of SDM. Both patient and provider 1) are involved; 2) share information; 3) express treatment preferences; and 4) agree to implement the treatment decision (23-25). Makoul and Clayman also argue for discussion of the patient's ability to achieve the treatment plan.(18)

Montori and colleagues have added that, for chronic conditions, a critical prerequisite for SDM is establishing an ongoing partnership.(8) The notion of partnership points to an essential element of SDM that has frequently been under-emphasized in the literature: the central role of the patient-provider relationship in the process of sharing decisions. (26-33) The importance of a productive patient-provider relationship in general has been underscored in the literature, connected to outcomes such as satisfaction, adherence, avoidance of malpractice claims, and treatment outcomes. (34-42) However, the notion of partnership is often forgotten in studies of SDM (even our own work). SDM studies tend to focus on a single clinical encounter. Even more limiting, studies typically focus only on the point where a 
decision is made in a consultation-in spite of the importance of the entire visit to productive SDM.(26;40;43) For example, Braddock's Informed Decision Making instrument (15) and Elywn's OPTION scale (21) both thoroughly evaluate the nature and quality of sharing decisions, and these scales have yielded valuable information about SDM (notably, that SDM does not occur very often). But these scales focus only on portions of the visit where decisions are discussed, to the exclusion of other potentially important elements in the clinical encounter.

3. SDM and the Entire Clinical Encounter

To study SDM effectively, the entire clinical encounter must be examined, not just the point when a decision is made. Indeed, no part of an interaction can be fully understood in isolation. What happens in the decision making process itself is inextricably linked to what happens before and after the decision. For example, if at the beginning of the visit a clinician uses a dominating, directive style with a patient, then later tries to involve the patient in a decision, the patient may be confused at best, uncomfortable and afraid to express an opinion at worst (44). Conversely, if the visit begins in a warm, welcoming manner and the clinician involves the patient from the beginning, patients will likely be more comfortable expressing preferences when decisions are made. For longitudinal relationships, these communication patterns are established and maintained over time, so that each clinic visit may be affected by previous visits.

Because SDM, the patient-provider relationship, and the entire clinical encounter are inextricably connected, it is helpful to examine a model of clinical interaction that emphasizes all elements of a consultation. The Four Habits Approach to Effective Clinical Communication (1-6), developed as a practical approach to teach physicians effective communication skills in 
a relatively short time, helps us to understand how SDM is connected to all parts of the encounter and to the patient-provider relationship. The model delineates four categories of behaviors critical for effective communication: 1 ) Invest in the beginning; 2) Elicit the patient's perspective; 3) Demonstrate empathy; and 4) Invest in the end (1). See Table 1.

Communication behaviors cannot be analyzed in isolation, and the Four Habits provides a means to examine SDM in the context of the patient-provider relationship and broader context of the clinical encounter.

Habit 1: Invest in the Beginning. The first few minutes of a consultation can have significant effects on the outcome of the visit, including how decisions are made.(1) For instance, creating rapport, one of the skills in Habit 1, is critical to create a welcoming atmosphere where patients are comfortable sharing information and opinions, about both health concerns and treatment options later in the visit.

Habit 1 includes planning the visit (i.e., agenda setting), which is essential to create an atmosphere conducive to SDM. $(26 ; 40 ; 43)$ Agenda setting allows the provider to check understanding of the patient's concerns and prioritize topics for discussion. Most importantly, the visit's agenda can be co-created with the patient, so both parties have input into what will be discussed, including negotiating priorities, which may be different. Framed another way, agenda setting is really the first SDM opportunity of the consultation.

Habit 2: Elicit the Patient's Perspective. Habit 2 continues to establish a foundation for a relationship characterized by equipoise and partnership. One skill for this habit is eliciting the patient's ideas about causes of the problem, including patient worries or fears.(45) Asking about their opinions and concerns allows the patient to be heard and feel valued, creating an 
atmosphere of openness and trust, an important requirement for SDM. More fundamentally, these activities are essential partnership-building behaviors.

Another skill in Habit 2 is identifying patient expectations, which sets the stage for making treatment decisions in a cooperative, collaborative manner, particularly because SDM depends on both parties expressing their preferences and concerns openly and honestly. The final skill in this habit, exploring the impact of the illness on the patient's life, follows naturally from the prior skill. Exploring the effect(s) of an illness allows the provider to show interest and concern for the patient-further building their partnership. Thus, Habit 2 specifies important partnership-building activities that lay the groundwork for successful SDM.

Habit 3: Demonstrate Empathy. Partnership building is further enhanced by expressing empathy. By being aware of patients' emotions, a provider can respond empathically both nonverbally (e.g., pause, touch) and with brief empathic statements (e.g., "I see how difficult this is for you."(2)). Communicating caring and empathy enhances the provider's credibility and trustworthiness. Indeed, the trust fostered by seeking to understand a patient's struggle may encourage the patient to reveal important diagnostic information and participate more fully in treatment decisions.(28;46-48) And, in potentially contentious situations, empathy can defuse discord and reduce each party's need to dominate.(49;50) Empathy also helps to foster a working alliance between patient and physician, allowing the sharing of an emotional bond and instrumental goals, such as partnering to identify treatment objectives, and deciding together how to realize these objectives. $(46 ; 51)$ In sum, demonstrating empathy creates important therapeutic consequences, many of which produce an optimal environment for SDM. 
Habit 4: Invest in the End. The final habit is where decision-making typically takes place. Other Habit 4 behaviors include delivery of diagnostic information and educating the patient. Important in these two behaviors is checking for patient understanding. "Teach backs," in which patients repeat in their own words the provider's information or instructions, are an effective way to determine patient understanding, but are rarely used.(15) Ensuring that the patient and provider have a shared understanding is an important prerequisite to SDM-and often occurs before a decision is ever deliberated.

Successful SDM is largely a function of multiple contextual elements and opportunities in the clinical encounter; it does not occur in isolation. Behaviors described in Habits 1-3 set the stage for an optimal SDM environment. Setting an agenda to ensure both parties' most important concerns are addressed, asking for patient input early in the visit (before discussing treatment decisions), and creating an atmosphere of trust and support using empathy, among other skills specified by the Four Habits, go a long way to invite active patient participation in treatment decisions, elicit patient uncertainties, and reach a decision to which both patient and provider are committed.(23)

4. Discussion and Conclusion

\subsection{Discussion}

The study of SDM is replete with challenges. Not all SDM interventions have been effective (7;52), and even widely used measures of SDM have had mixed support. In a recent study comparing two widely used SDM measurement tools, the OPTION scale and the Informed Decision Making instrument, there were generally low levels of agreement between the two 
tools.(25) Study authors suggested these findings may be attributable in part to the inherent difficulty in capturing and measuring SDM in observable, quantifiable terms. As a result, there may be a tendency to focus on the most easily observable behaviors, which might not capture the complexity of SDM.

Our point echoes this notion: SDM is more complex than the moment an exchange about a decision begins. SDM is shaped by the context of the entire clinical encounter and the nature (e.g., alliance, trust) of the patient-provider relationship (especially long-term relationships). If the overall encounter contains suboptimal communication, the patientprovider relationship is not characterized by trust, or even if a generally positive relationship lacks equipoise, then it is unreasonable to expect that communication will suddenly improve when a decision must be made.

\subsection{Conclusion}

Research on SDM has made important strides: We have learned more about how decisions are made, and how this process can be improved. However, given our knowledge of communication, studying SDM in isolation is analogous to an outsider walking in on the middle of a conversation and making perfect sense of it. SDM cannot be separated from the rest of the clinical encounter, nor from the patient-provider relationship. The challenge for us as researchers is to broaden our conception of what SDM is and how it is achieved. By examining SDM as a part of a larger conversation (and relationship), we have the potential to reach a new and more complete understanding of SDM, and in turn create more effective communication approaches for patients and providers. 


\subsection{Practice Implications}

The contextual nature of SDM has important implications for teaching SDM skills. Current interventions have had limited effectiveness in fostering open, trusting relationships. Moreover, SDM interventions frequently ignore other potentially critical parts of the encounter $(7 ; 53)$. As we have argued, the simple act of setting an agenda might prove invaluable to enhance SDM $(26 ; 43)$. This and other behaviors specified in the Four Habits and other communication approaches can go a long way toward engaging patients in their own care. Empirical studies will be needed to determine which behaviors produce the greatest levels of patient engagement and optimal SDM. 


\section{Reference List}

(1) Frankel RM, Stein T. Getting the most out of the clinical encounter: the four habits model. Journal of Medical Practice Management 2001 Jan;16(4):184-91.

(2) Stein T, Krupat E, Frankel RM. Talking with patients using the four habits model. 2011. The Permanente Medical Group.

(3) Frankel RM, Stein TS, Krupat E. The four habits approach to effective clinical communication. 2003. Physician Education and Development, Kaiser Permanente Northern California Region.

(4) Gulbrandsen P, Krupat E, Benth JS, Garratt A, Safran DG, Finset A, et al. "Four Habits" goes abroad: report from a pilot study in Norway. Patient Education \& Counseling 2008 Sep;72(3):388-93.

(5) Krupat E, Frankel R, Stein T, Irish J. The Four Habits Coding Scheme: Validation of an instrument to assess clinicians' communication behavior. Patient Education and Counseling $2006 \mathrm{Jul} ; 62(1): 38-45$.

(6) Runkle C, Wu E, Wang EC, Gordon GH, Frankel R. Clinician confidence about conversations at the end of life is strengthened using the four habits approach. Journal of Psychosocial Oncology 26(3):81-95, 2008.

(7) Legare F, Ratte S, Kryworuchko J, Gravel K, Graham ID, Turcotte S. Interventions for improving the adoption of shared decision making by healthcare professionals (Review). Cochrane Database of Systematic Reviews 2010;5. 
(8) Montori VM, Gafni A, Charles C. A shared treatment decision-making approach between patients with chronic conditions and their clinicians: the case of diabetes. Health Expectations 2006 Mar;9(1):25-36.

(9) Karnieli-Miller O, Salyers MP. Clinical communications with persons who have severe mental illnesses. Serious Mental Illnesses (SMI): Person-centered Approaches.Abingdon, U.K.: Radcliffe Publishing; 2010.

(10) Young HN, Bell RA, Epstein RM, Feldman MD, Kravitz RL. Physicians' Shared DecisionMaking Behaviors in Depression Care. Arch Intern Med 2008 Jul 14;168(13):1404-8.

(11) Drake RE, Deegan PE. Shared decision making is an ethical imperative. Psychiatr Serv 2009;60(8):1007.

(12) Straub C, Nebling T, Mnller H. Translating research into practice: A German sickness fund supporting patient participation. Patient Education and Counseling 2008 Dec;73(3):544-50.

(13) King JS, Moulton BW. Re-thinking informed consent: the case for shared medical decision making. American Journal of Law and Medicine 2006;32:429-501.

(14) Katz J. The silent world of doctor and patient. 1984. Baltimore, MD, Johns Hopkins University Press.

(15) Braddock CH, Edwards KA, Hasenberg NM, Laidley TL, Levinson W. Informed Decision Making in Outpatient Practice: Time to Get Back to Basics. JAMA: The Journal of the American Medical Association 1999 Dec 22;282(24):2313-20. 
(16) Deegan PE, Drake RE. Shared Decision Making and Medication Management in the Recovery Process. Psychiatr Serv 2006 Nov 1;57(11):1636-9.

(17) Duncan E, Best C, Hagen S. Shared decision making interventions for people with mental health conditions. Cochrane Database of Systematic Reviews 2010;1.

(18) Makoul G, Clayman ML. An integrative model of shared decision making in medical encounters. Patient Education and Counseling 2006 Mar;60(3):301-12.

(19) Towle A, Godolphin W. Framework for teaching and learning informed shared decision making. BMJ 1999 Sep 18;319(7212):766-9.

(20) Whitney SN, McGuire AL, McCullough LB. A Typology of Shared Decision Making, Informed Consent, and Simple Consent. Annals of Internal Medicine 2003;140(1):54-60.

(21) Elwyn G, Edwards A, Wensing M, Hood K, Atwell C, Grol R. Shared decision making: developing the OPTION scale for measuring patient involvement. Qual Saf Health Care 2003 Apr 1;12(2):93-9.

(22) Street RL, Haidet P. How well do doctors know their patients? Factors affecting physicians' understanding of patients' health beliefs. Journal of General Internal Medicine 2011;26:21-7.

(23) Charles C, Gafni A, Whelan T. Shared decision-making in the medical encounter: What does it mean? (or it takes at least two to tango). Social Science \& Medicine 1997 Mar;44(5):681-92. 
(24) Charles C, Gafni A, Whelan T. Decision-making in the physician-patient encounter: revisiting the shared treatment decision-making model. Social Science \& Medicine 1999 Sep;49(5):651-61.

(25) Weiss MC, Peters TJ. Measuring shared decision making in the consultation: a comparison of the OPTION and Informed Decision Making instruments. Patient Education \& Counseling 2008;70:79-86.

(26) Brock DM, Mauksch LB, Witteborn S, Nagasawa P, Robins LS. Effectiveness of intensive physician training in upfront agenda setting. Journal of General Internal Medicine 2011;26:1317-23.

(27) Stewart M, Brown JB, Donner A, McWhinney IR, Oates J, Weston WW, et al. The impact of patient-centered care on outcomes. Journal of Family Practice 2000 Sep;49(9):796804.

(28) Stewart M, Brown JB, Weston WW, McWhinney IR, McWilliam CL, Freeman TR. PatientCentered Medicine: Transforming the Clinical Method. Thousand Oaks, CA: Sage; 1995.

(29) Van Dulmen AM, Bensing JM. Health promoting effects of the physician-patient encounter. Psychology, Health \& Medicine 2002 Aug;7(3):289-300.

(30) Lazare A, Eisenthal S, Wasserman L. The customer approach to patienthood: attending to patient requests in a walk0in clinic. Arch Gen Psychiatry 1975;32(5):553-8. 
(31) Beckman HB, Markakis KM, Suchman AL, Frankel RM. The doctor-patient relationship and malpractice: lessons from plaintiff depositions. Arch Intern Med 1994;154(12):136570.

(32) Quill TE. Partnerships in patient care: a contractual approach. Annals of Internal Medicine 1983;98:228-34.

(33) Dwamena F, Holmes-Rovner M, Gaulden CM, Jorgenson S, Sadigh G, Lewin S, et al. Interventions for providers to promote a patient-centred approach in clinical consultations. Cochrane Database of Systematic Reviews 2012;12.

(34) Davis K, Schoenbaum SC, Audet AM. A 2020 vision of patient-centered primary care. JGIM: Journal of General Internal Medicine 2005 Oct;20(10):953-7.

(35) Engel GL. The Need for a New Medical Model: A Challenge for Biomedicine. Science 1977 Apr 8;196(4286):129-36.

(36) Fiscella K, Meldrum S, Franks P, Cleveland GS, Duberstein P, McDaniel SH, et al. Patient trust: is it related to patient-centered behavior of primary care physicians? Medical Care 2004;42(11):1049-55.

(37) Hall JA, Horgan TG, Stein TS, Roter DL. Liking in the physician-patient relationship. Patient Education and Counseling 2002 Sep;48(1):69-77.

(38) Kaplan SH, Greenfield SG, Ware JE. Assessing the effects of physician-patient interactions on the outcomes of chronic disease. Medical Care 1989;27(3):S110-S127. 
(39) Makoul G. Essential elements of communication in medical encounters: the Kalamazoo Consensus Statement. Academic Medicine 2001 Apr;76(4):390-3.

(40) Rodriguez H, Anastario M, Frankel R, Odigie E, Rogers W, von Glahn T, et al. Can teaching agenda-setting skills to physicians improve clinical interaction quality? A controlled intervention. BMC Medical Education 2008;8(1):3.

(41) Levinson W, Roter DL, Mullooly JP, Dull VT, Frankel RM. Physician-patient communication: the relationship with malpractice claims among primary care physicians and surgeons. JAMA 1997;277(7):553-9.

(42) Levinson W. Physician-patient communication: a key to malpractice prevention. JAMA 1994;272(20):1619-20.

(43) Mauksch LB, Hillenburg L, Robins L. The establishing focus protocol: training for collaborative agenda setting and time management in the medical interview. Families, Systems, \& Health 2001;19(2):147-57.

(44) Frosch DL, May SG, Rendle KAS, Tietbohl C, Elwyn G. Authoritarian physicians and patients' fear of being labeled "difficult" among key obstacles to shared decision making. Health Affairs 2012;31(5):1030-8.

(45) Kleinman A. Patients and healers in the context of culture. Berkeley, CA: University of California Press; 1980. 
(46) Mead N, Bower P. Patient-centredness: a conceptual framework and review of the empirical literature. Social Science \& Medicine 2000 Oct 1;51(7):1087-110.

(47) Banja JD. Toward a more empathic relationship in pain medicine. Pain Medicine 2008 Nov;9(8):1125-9.

(48) Matthias MS, Parpart AL, Nyland KA, Huffman MA, Stubbs DL, Sargent C, et al. The patient-provider relationship in chronic pain care: providers' perspectives. Pain Medicine 2010;11:1688-97.

(49) Tait RC. Empathy: necessary for effective pain management? Current Pain and Headache Reports 2008;12:108-12.

(50) Eggly S, Tzelepis A. Relational control in difficult physician-patient encounters: negotiating treatment for pain. Journal of Health Communication 2001;6(4):323-33.

(51) Fuertes JN, Mislowack A, Bennett J, Paul L, Gilbert TC, Fontan G, et al. The physicianpatient working alliance. Patient Education \& Counseling 2007;66(1):29-36.

(52) Joosten EA, DeFuentes-Merrilas L, de Weert GH, Sensky T, van der Staak CP, de Jong CA. Systematic review of the effects of shared decision-making on patient satisfaction, treatment adherence, and health status. Psychotherapy and Psychosomatics $2008 ; 77(4): 219-26$ 
(53) Haywood K, Marshall S, Fitzpatrick R. Patient participation in the consultation process: a structured review of intervention strategies. Patient Education \& Counseling 2006;63:12-23. 
Table 1: Selected Skill Areas of The Four Habits Approach

\begin{tabular}{|ll|}
\hline Habit & Communication Behaviors \\
\hline Habit 1: Invest in the Beginning & - Creating rapport quickly \\
& - Eliciting full spectrum of patient concerns \\
& - Planning the visit with the patient \\
\hline Habit 2: Elicit the Patient's Perspective & $\begin{array}{l}\text { - Assessing patient attribution } \\
\text { - Identifying patient requests } \\
\end{array}$ \\
& - Exploring impact of symptoms on patient's life \\
\hline Habit 3: Demonstrating Empathy & - Responding to patients' emotions \\
& - Discerning empathic opportunities \\
& - Expressing empathy verbally and nonverbally \\
\hline Habit 4: Invest in the End & Delivering diagnostic information \\
& - Engaging in shared decision-making \\
& - Closing the visit (asking for additional questions, \\
& confirming next steps, ending on a personal note) \\
\hline
\end{tabular}

Reference List

(1) Frankel RM, Stein T. Getting the most out of the clinical encounter: the four habits model. Journal of Medical Practice Management 2001 Jan;16(4):184-91.

(2) Stein T, Krupat E, Frankel RM. Talking with patients using the four habits model. 2011. The Permanente Medical Group.

Ref Type: Pamphlet

(3) Frankel RM, Stein TS, Krupat E. The four habits approach to effective clinical communication. 2003. Physician Education and Development, Kaiser Permanente Northern California Region. Ref Type: Pamphlet

(4) Gulbrandsen P, Krupat E, Benth JS, Garratt A, Safran DG, Finset A, et al. "Four Habits" goes abroad: report from a pilot study in Norway. Patient Education \& Counseling 2008 Sep;72(3):388-93.

(5) Krupat E, Frankel R, Stein T, Irish J. The Four Habits Coding Scheme: Validation of an instrument to assess clinicians' communication behavior. Patient Education and Counseling 2006 Jul;62(1):38-45.

(6) Runkle C, Wu E, Wang EC, Gordon GH, Frankel R. Clinician confidence about conversations at the end of life is strengthened using the four habits approach. Journal of Psychosocial Oncology 26(3):81-95, 2008. 
(7) Legare F, Ratte S, Kryworuchko J, Gravel K, Graham ID, Turcotte S. Interventions for improving the adoption of shared decision making by healthcare professionals (Review). Cochrane Database of Systematic Reviews 2010;5.

(8) Montori VM, Gafni A, Charles C. A shared treatment decision-making approach between patients with chronic conditions and their clinicians: the case of diabetes. Health Expectations 2006 Mar;9(1):25-36.

(9) Karnieli-Miller O, Salyers MP. Clinical communications with persons who have severe mental illnesses. Serious Mental Illnesses (SMI): Person-centered Approaches.Abingdon, U.K.: Radcliffe Publishing; 2010.

(10) Young HN, Bell RA, Epstein RM, Feldman MD, Kravitz RL. Physicians' Shared Decision-Making Behaviors in Depression Care. Arch Intern Med 2008 Jul 14;168(13):1404-8.

(11) Drake RE, Deegan PE. Shared decision making is an ethical imperative. Psychiatr Serv 2009;60(8):1007.

(12) Straub C, Nebling T, Mnller H. Translating research into practice: A German sickness fund supporting patient participation. Patient Education and Counseling 2008 Dec;73(3):544-50.

(13) King JS, Moulton BW. Re-thinking informed consent: the case for shared medical decision making. American Journal of Law and Medicine 2006;32:429-501.

(14) Katz J. The silent world of doctor and patient. 1984. Baltimore, MD, Johns Hopkins University Press.

Ref Type: Online Source

(15) Braddock CH, Edwards KA, Hasenberg NM, Laidley TL, Levinson W. Informed Decision Making in Outpatient Practice: Time to Get Back to Basics. JAMA: The Journal of the American Medical Association 1999 Dec 22;282(24):2313-20.

(16)

Deegan PE, Drake RE. Shared Decision Making and Medication Management in the Recovery Process. Psychiatr Serv 2006 Nov 1;57(11):1636-9.

(17) Duncan E, Best C, Hagen S. Shared decision making interventions for people with mental health conditions. Cochrane Database of Systematic Reviews 2010;1.

(18) Makoul G, Clayman ML. An integrative model of shared decision making in medical encounters. Patient Education and Counseling 2006 Mar;60(3):301-12.

(19) Towle A, Godolphin W. Framework for teaching and learning informed shared decision making. BMJ 1999 Sep 18;319(7212):766-9.

(20) Whitney SN, McGuire AL, McCullough LB. A Typology of Shared Decision Making, Informed Consent, and Simple Consent. Annals of Internal Medicine 2003;140(1):54-60. 
(21) Elwyn G, Edwards A, Wensing M, Hood K, Atwell C, Grol R. Shared decision making: developing the OPTION scale for measuring patient involvement. Qual Saf Health Care 2003 Apr 1;12(2):93-

9.

(22) Street RL, Haidet P. How well do doctors know their patients? Factors affecting physicians' understanding of patients' health beliefs. Journal of General Internal Medicine 2011;26:21-7.

(23) Charles C, Gafni A, Whelan T. Shared decision-making in the medical encounter: What does it mean? (or it takes at least two to tango). Social Science \& Medicine 1997 Mar;44(5):681-92.

(24) Charles C, Gafni A, Whelan T. Decision-making in the physician-patient encounter: revisiting the shared treatment decision-making model. Social Science \& Medicine 1999 Sep;49(5):651-61.

(25) Weiss MC, Peters TJ. Measuring shared decision making in the consultation: a comparison of the OPTION and Informed Decision Making instruments. Patient Education \& Counseling 2008;70:79-86.

(26) Brock DM, Mauksch LB, Witteborn S, Nagasawa P, Robins LS. Effectiveness of intensive physician training in upfront agenda setting. Journal of General Internal Medicine 2011;26:1317-23.

(27) Stewart M, Brown JB, Donner A, McWhinney IR, Oates J, Weston WW, et al. The impact of patient-centered care on outcomes. Journal of Family Practice 2000 Sep;49(9):796-804.

(28) Stewart M, Brown JB, Weston WW, McWhinney IR, McWilliam CL, Freeman TR. PatientCentered Medicine: Transforming the Clinical Method. Thousand Oaks, CA: Sage; 1995.

(29) Van Dulmen AM, Bensing JM. Health promoting effects of the physician-patient encounter. Psychology, Health \& Medicine 2002 Aug;7(3):289-300.

(30) Lazare A, Eisenthal S, Wasserman L. The customer approach to patienthood: attending to patient requests in a walk0in clinic. Arch Gen Psychiatry 1975;32(5):553-8.

(31) Beckman HB, Markakis KM, Suchman AL, Frankel RM. The doctor-patient relationship and malpractice: lessons from plaintiff depositions. Arch Intern Med 1994;154(12):1365-70.

(32) Quill TE. Partnerships in patient care: a contractual approach. Annals of Internal Medicine 1983;98:228-34.

(33) Dwamena F, Holmes-Rovner M, Gaulden CM, Jorgenson S, Sadigh G, Lewin S, et al. Interventions for providers to promote a patient-centred approach in clinical consultations. Cochrane Database of Systematic Reviews 2012;12.

(34) Davis K, Schoenbaum SC, Audet AM. A 2020 vision of patient-centered primary care. JGIM: Journal of General Internal Medicine 2005 Oct;20(10):953-7.

(35) Engel GL. The Need for a New Medical Model: A Challenge for Biomedicine. Science 1977 Apr 8;196(4286):129-36. 
(36) Fiscella K, Meldrum S, Franks P, Cleveland GS, Duberstein P, McDaniel SH, et al. Patient trust: is it related to patient-centered behavior of primary care physicians? Medical Care 2004;42(11):1049-55.

(37) Hall JA, Horgan TG, Stein TS, Roter DL. Liking in the physician-patient relationship. Patient Education and Counseling 2002 Sep;48(1):69-77.

(38) Kaplan SH, Greenfield SG, Ware JE. Assessing the effects of physician-patient interactions on the outcomes of chronic disease. Medical Care 1989;27(3):S110-S127.

(39) Makoul G. Essential elements of communication in medical encounters: the Kalamazoo Consensus Statement. Academic Medicine 2001 Apr;76(4):390-3.

(40) Rodriguez H, Anastario M, Frankel R, Odigie E, Rogers W, von Glahn T, et al. Can teaching agenda-setting skills to physicians improve clinical interaction quality? A controlled intervention. BMC Medical Education 2008;8(1):3.

(41) Levinson W, Roter DL, Mullooly JP, Dull VT, Frankel RM. Physician-patient communication: the relationship with malpractice claims among primary care physicians and surgeons. JAMA 1997;277(7):553-9.

(42) Levinson W. Physician-patient communication: a key to malpractice prevention. JAMA 1994;272(20):1619-20.

(43) Mauksch LB, Hillenburg L, Robins L. The establishing focus protocol: training for collaborative agenda setting and time management in the medical interview. Families, Systems, \& Health 2001;19(2):147-57.

(44) Frosch DL, May SG, Rendle KAS, Tietbohl C, Elwyn G. Authoritarian physicians and patients' fear of being labeled "difficult" among key obstacles to shared decision making. Health Affairs 2012;31(5):1030-8.

(45) Kleinman A. Patients and healers in the context of culture. Berkeley, CA: University of California Press; 1980.

(46) Mead N, Bower P. Patient-centredness: a conceptual framework and review of the empirical literature. Social Science \& Medicine 2000 Oct 1;51(7):1087-110.

(47) Banja JD. Toward a more empathic relationship in pain medicine. Pain Medicine 2008 Nov;9(8):1125-9.

(48) Matthias MS, Parpart AL, Nyland KA, Huffman MA, Stubbs DL, Sargent C, et al. The patientprovider relationship in chronic pain care: providers' perspectives. Pain Medicine 2010;11:168897.

(49) Tait RC. Empathy: necessary for effective pain management? Current Pain and Headache Reports 2008;12:108-12. 
(50) Eggly S, Tzelepis A. Relational control in difficult physician-patient encounters: negotiating treatment for pain. Journal of Health Communication 2001 Oct;6(4):323-33.

(51) Fuertes JN, Mislowack A, Bennett J, Paul L, Gilbert TC, Fontan G, et al. The physician-patient working alliance. Patient Education \& Counseling 2007;66(1):29-36.

(52) Joosten EA, DeFuentes-Merrilas L, de Weert GH, Sensky T, van der Staak CP, de Jong CA. Systematic review of the effects of shared decision-making on patient satisfaction, treatment adherence, and health status. Psychotherapy and Psychosomatics 2008;77(4):219-26.

(53) Haywood K, Marshall S, Fitzpatrick R. Patient participation in the consultation process: a structured review of intervention strategies. Patient Education \& Counseling 2006;63:12-23. 